\section{Research Topics in Gastrointestinal Disease: A report on the 10 th meeting and an announcement of the 11th meeting}

Organizing Committee:

Nicola Jones MD PhD FRCPC, University of Toronto, Toronto, Ontario

Ken Croitoru MD FRCPC, University of Toronto, Toronto, Ontario

Stephen Vanner MD MSc FRCPC, Chair, CAG Research Committee;

Queen's University, Kingston, Ontario

Rohini Soni, Chief Research Officer, Crohn's and Colitis Foundation of Canada

Louise Hope, CAG National Office

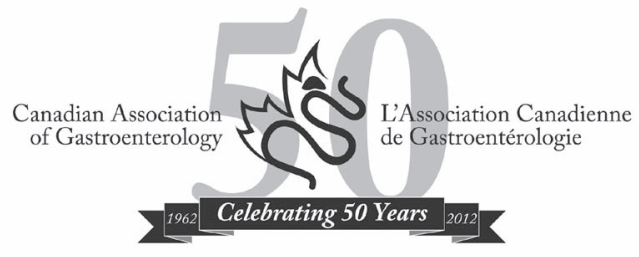

ACKNOWLEDGEMENTS: The organizers thank the CCFC for helping to support this meeting. In addition, we thank the invited faculty, Drs Carla Coffin and Gil Kaplan, for their commitment and valuable contributions to this meeting.

\section{PARTICIPANTS AND FACULTY IN THE 10TH SYMPOSIUM ON RESEARCH TOPICS IN GASTROINTESTINAL DISEASE, FEBRUARY 24 TO 25, 2011.}

Participants: Joannie Allaire, Sherbrooke, Quebec; Daniela Ardelean, Toronto, Ontario; Francisco Bautista-Cruz, Kingston, Ontario; Manmish Bawa, Calgary, Alberta; Mamatha Bhat, Montreal, Quebec; Cristina Bosoi, Montreal, Quebec, Jean-Francois Bourzac, Sherbrooke, Quebec; Francois Brial, Sherbrooke, Quebec; Qi Cao, Bedford, Nova Scotia; Ran Chen, Edmonton, Alberta; Josh Collins, Hamilton, Ontario; James Cotton, Calgary, Alberta; Genevieve Coulombe, Sherbrooke, Quebec; Elnaz Hoshivar, Calgary, Alberta; Lisa Kish, Edmonton, Alberta; Vanessa Kissoon-Singh, Calgary, Alberta; Tamia Lapointe, Calgary, Alberta; Joshua Lee, Calgary, Alberta; Manon Lepage, Sherbrooke, Quebec; Allen Lim, Calgary, Alberta; Mark Lukewich, Kingston, Ontario; Ryan Mathias, Calgary, Alberta; Travis Murdoch, Toronto, Ontario; Vivek Philip, Toronto, Ontario; L Patrick Schenck, Calgary, Alberta; Amira Seltana, Sherbrooke, Quebec; Victor Tso, Edmonton, Alberta; Sarah Tulk, Calgary, Alberta; Sara Turner, Calgary, Alberta; Aman Wadhwani, Calgary, Alberta. Faculty: Dr Carla Coffin, Calgary, Alberta; Dr Ken Croitoru, Toronto, Ontario; Dr Nicola Jones, Toronto, Ontario; Dr Gil Kaplan, Calgary, Alberta; Dr Steve Vanner, Kingston, Ontario.

\section{SAVE THE DATE: RESEARCH TOPICS IN GI DISEASE XI, FEBRUARY 22 TO 23, 2012}

The CAG's Research Topics in GI Disease provides a unique opportunity for graduate students, $\mathrm{PhD}$ and MD postdoctoral trainees, including adult or pediatric trainees (beyond their core training, ie, 'PGY5/ PGY6') engaged in GI research, to attend the 11th Annual Research Topics in GI Disease Meeting (February 22 to 23, 2012) being held directly in advance of CDDW 2012 in Montreal, Quebec. This small group meeting provides an intimate setting for participants to present their research findings, and to engage in career development workshops

The CAG is proud to acknowledge its Benefactor Corporate Sponsors:

Abbott Canada
AstraZeneca Canada Inc
Olympus Canada Inc

Merck \& Co Inc
Takeda Canada Inc 
and skill building exercises among enthusiastic expert faculty in the field. In addition, participants will be able to register to attend CDDW 2012 and take advantage of trainee-focused events including the trainee workshop (small group session focused on research opportunities as well as application writing), faculty-directed poster reviewing sessions, key lectures (Young Investigator Award Lecture, Research Excellence Award Lecture) among many other sessions at CDDW.

Applicants must submit an abstract (using the CDDW meeting's online abstract system). Abstracts will be reviewed, ranked and selected by the CAG Research Committee. Abstracts that are accepted to the Research Topics meeting are also considered for presentation at the CDDW meeting.

Funding will be available to support transportation to the Research Topics in GI Disease meeting and cover the cost of shared accommodation during the Research Topics course. Limited spots will be available on a competitive basis. The call for abstracts will be issued in early September. Stay tuned to the CAG website at www.cag-acg.org for more information.

\section{SOME PAST RESEARCH TOPICS MEETING PHOTOS:}

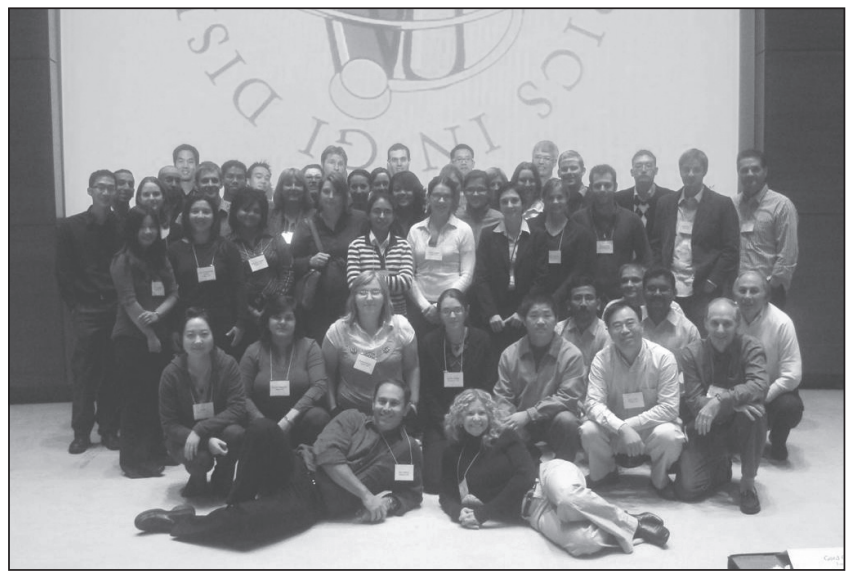

Research Topics in GI Disease VII, October 12 to 14, 2007, King City, Ontario

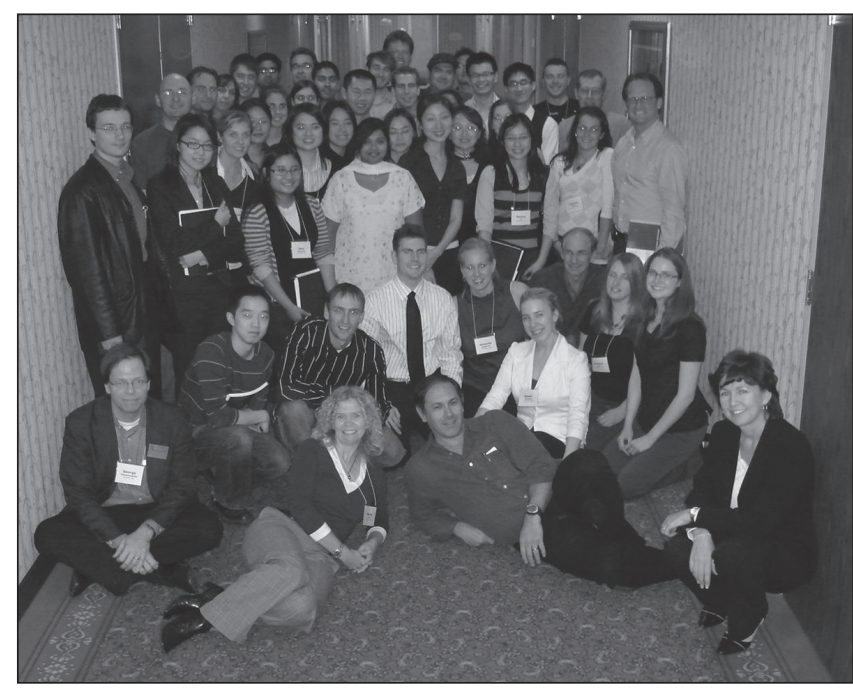

Research Topics in GI Disease VIII, October 24 to 26, 2008, Toronto, Ontario

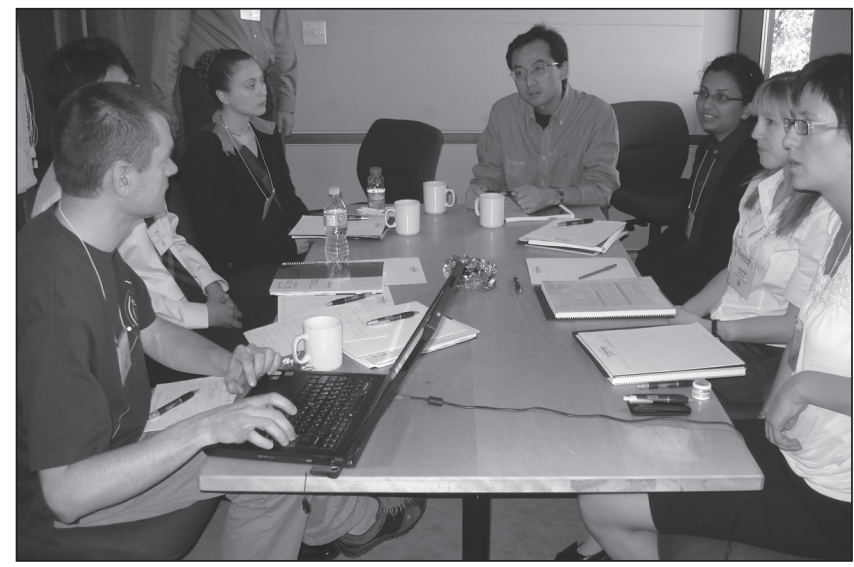

A group assignment at Research Topics in GI Disease IX, October 16 to 18, 2009, King City, Ontario 


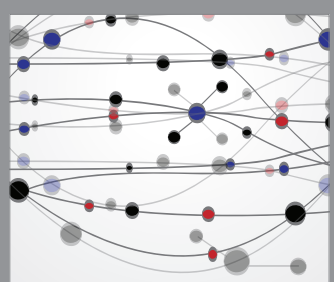

The Scientific World Journal
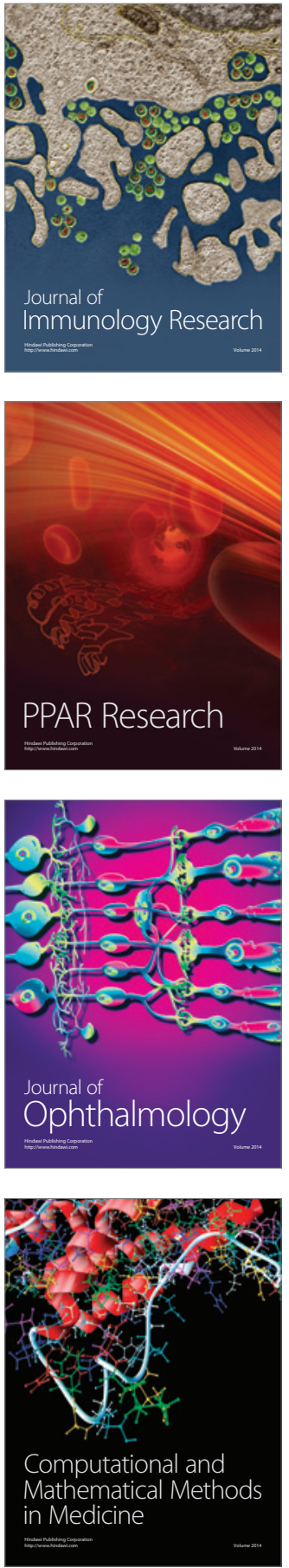

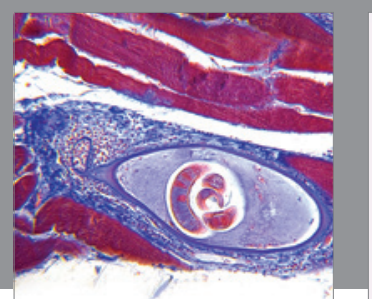

Gastroenterology Research and Practice

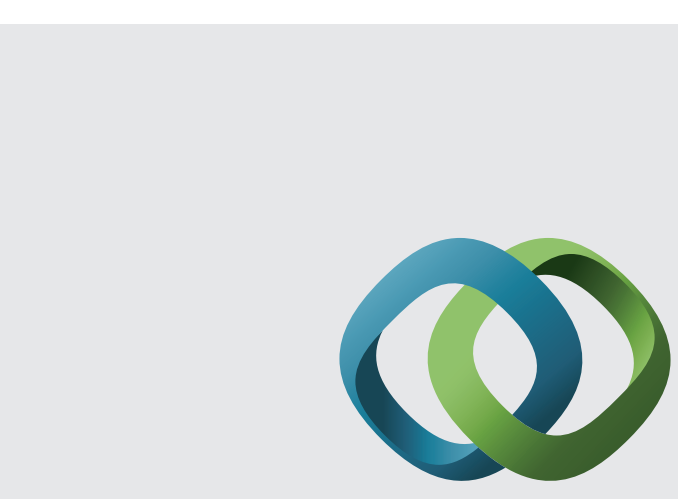

\section{Hindawi}

Submit your manuscripts at

http://www.hindawi.com
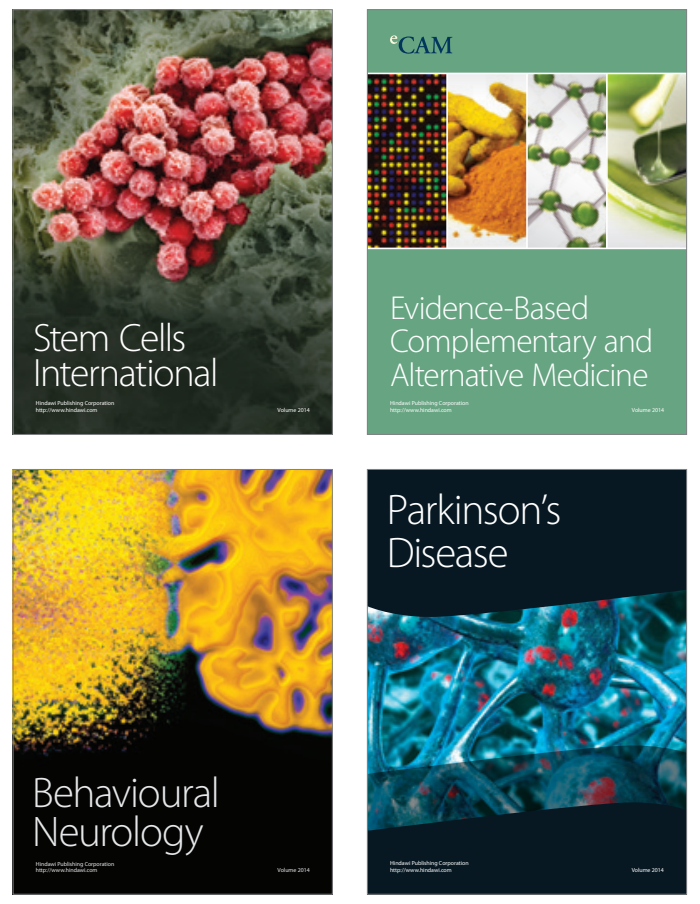
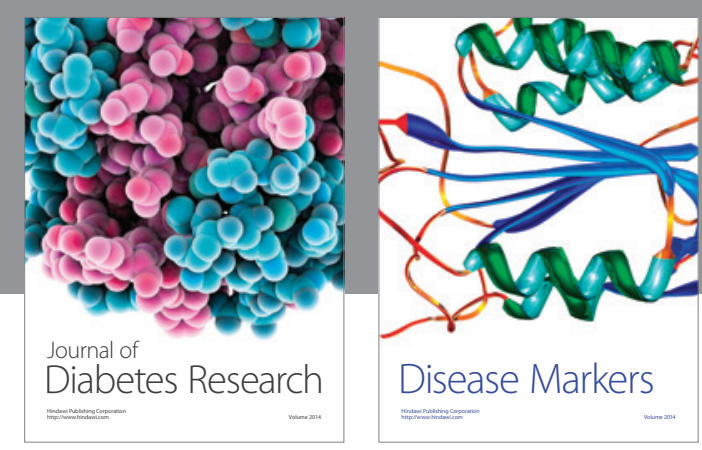

Disease Markers
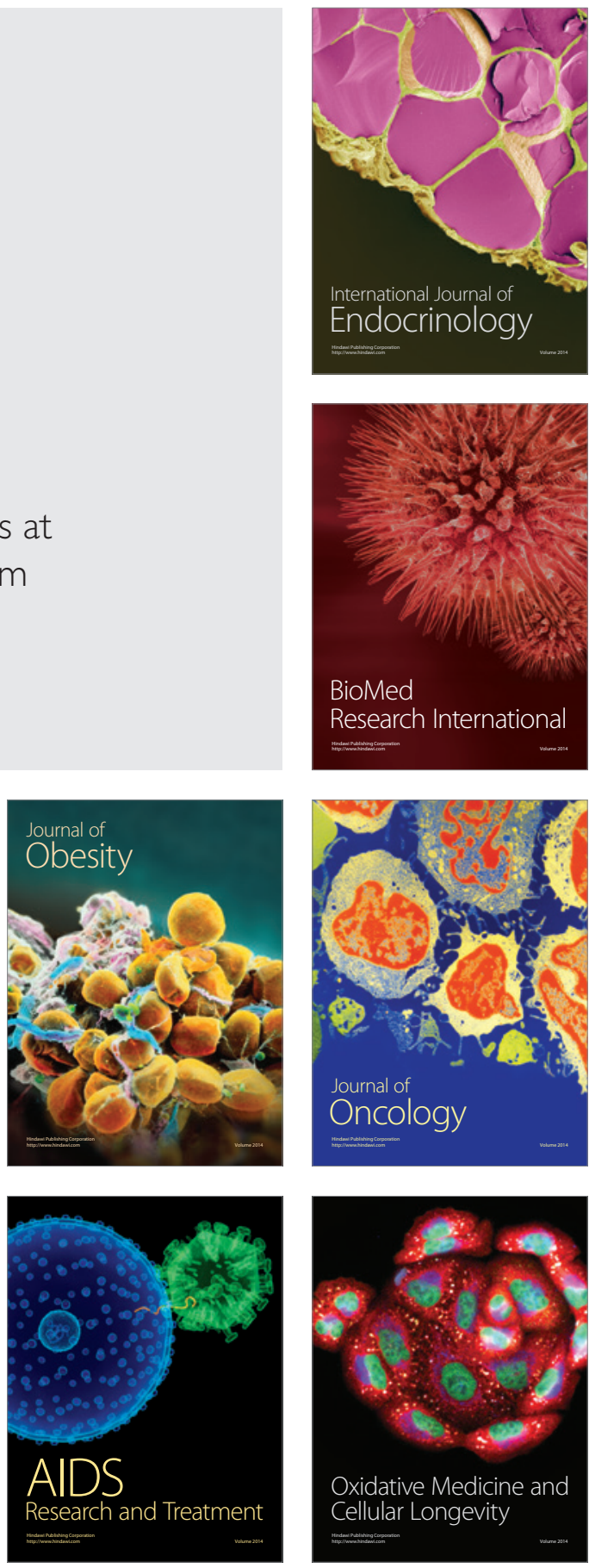